\title{
Komparasi Jalur Moneter untuk Stabilitas Harga \\ Dalam Kerangka Inflation Targeting Framework \\ (Studi kasus pada interest rate, exchange rate dan credit channel)
}

\author{
Setyo Tri Wahyudi*, Rinny Apriliany Zakaria, Nurul Badriyah \\ Fakultas Ekonomi dan Bisnis, Universitas Brawijaya, Indonesia
}

\begin{abstract}
The monetary policy transmission mechanism has many ways in influencing inflation. This method became known as the monetary path. The use of appropriate channels in monetary policy will affect whether or not the objectives of the monetary policy are achieved. This study aims to determine which monetary path is appropriate for Indonesia, which is a developing country with an open economic system. The data used are secondary data taken from Bank Indonesia for the period 2005 to 2016. The research variables include inflation, BI-rate, credit interest rates (SBB), gross domestic product (GDP), exchange rate, bank reserve (BBR), and the amount of credit extended. This study focuses on the path of interest rates, exchange rates and bank credit using the Error Correction Model (ECM). The results of this study indicate that the right monetary path for Indonesia is the credit channel. This is because the value of the Error Correction Term (ECT) coefficient on the ECM model shows that the coefficient of the credit channel is smaller than the interest rate and exchange rate channel, which means that the imbalance that occurs can be resolved more quickly with the credit channel.
\end{abstract}

JEL : E43, E52, C53

Keywords : interest rate channel, exchange rate channel, credit view channel, inflation targeting framework, error correction model

\section{PENDAHULUAN}

Kebijakan moneter merupakan kebijakan otoritas moneter atau Bank Sentral dalam bentuk pengendalian besaran moneter untuk mencapai perkembangan kegiatan perekonomian yang diinginkan (Warjiyo \& Solikin, 2003). Kebijakan moneter merupakan bagian dari kebijakan ekonomi secara makro yang mempertimbangkan siklus kegiatan, sifat, dan faktor-faktor kegiatan ekonomi suatu negara serta memiliki dampak yang luas, meliputi ekonomi makro (Alia \& Anwar, 2017; Rüth, 2017), sektor riil (Aleem, 2010; Rüth, 2017), rumah tangga (Mengesha \& Holmes, 2013; Voinea, Lovin, \& Cojocaru, 2018), dan variabel keuangan (Lombardia, Siklos, \& Xiec, 2018). Dalam penerapannya, masing-masing negara memiliki strategi sendiri berdasarkan tujuan dan mekanisme transmisi yang diyakini sesuai untuk perekonomian negara tersebut.

*Email : setyo.tw@ub.ac.id

Received : 18-07-2019, Accepted : 23-07-2019, Published: 19-12-2019

P-ISSN : 2087-9954, E-ISSN : 2550-0066. DOI : http://dx.doi.org/10.26418/jebik.v8i3.34350 
Rancang bangun kebijakan moneter memiliki tiga terminologi yang sering digunakan, yaitu target akhir, indikator atau target antara, dan instrumen moneter (Warjiyo \& Solikin, 2003). Target atau sasaran akhir adalah kondisi yang ingin dicapai dari sebuah kebijakan moneter. Pada umumnya, target atau sasaran akhir kebijakan moneter di beberapa negara meliputi, pertumbuhan ekonomi dan pemerataan pendapatan, kesempatan kerja, kestabilan harga, dan keseimbangan neraca pembayaran. Idealnya, semua sasaran akhir tersebut ingin dicapai secara simultan. Namun, kenyataannya dalam menjalankan dua atau tiga sasaran akhir tersebut masih cukup sulit, karena antara sasaran satu dan lainnya terdapat trade-off berkaitan dengan manfaat dan dampak yang diperoleh. Selanjutnya, indikator atau target antara dalam kebijakan moneter adalah penghubung terhadap sasaran akhir. Sasaran antara digunakan untuk mengetahui indikasi dari kebijakan moneter terhadap sasaran akhirnya. Beberapa pilihan sasaran antara yang dapat digunakan antara lain M1, M2 (dari sisi pasiva neraca sistem moneter), kredit perbankan (dari sisi aktiva neraca sistem moneter) dan suku bunga (Ascarya, 2002).

Untuk mencapai sasaran antara, otoritas moneter membutuhkan sasaran operasional agar proses transmisi kebijakan moneter dapat terlaksana sesuai rencana. Adapun sasaran-sasaran operasional yang dapat digunakan adalah uang primer (quantity-based approach) dan suku bunga (price-based approach) jangka pendek. Selanjutnya, instrumen-instrumen moneter dapat dianalogikan sebagai alat yang digunakan otoritas moneter untuk mengarahkan kebijakan moneter ke tujuan tertentu sebagaimana yang diinginkan.

Berkaitan dengan pencapaian sasaran akhir, berdasarkan amanat UU No. 23 tahun 1999 mengenai Bank Indonesia yang telah diamandemen dengan UU No. 3 tahun 2004, menetapkan bahwa tujuan utama pelaksanaan kebijakan moneter di Indonesia yang dikenal dengan single objective, adalah untuk mencapai dan memelihara kestabilan nilai Rupiah (Heroika, 2011). Stabilitas nilai Rupiah tersebut tercermin pada laju inflasi yang rendah dan stabil (Warjiyo \& Solikin, 2003). Menindaklanjuti ketetapan undang-undang tersebut, maka otoritas moneter memutuskan untuk melaksanakan kerangka kebijakan moneter yang baru melalui inflation targeting framework pada Juli 2005. Dalam kerangka baru ini, otoritas moneter berharap kebijakan yang diterapkan akan menjadi lebih jelas, terfokus, transparan dan akuntabel, sehingga dapat menurunkan ekspektasi inflasi (Heroika, 2011). Adapun sasaran operasional yang digunakan dalam kebijakan ini adalah pengendalian suku bunga oleh otoritas moneter, yang sebelumnya menggunakan jumlah uang beredar.

Literatur yang membahas jalur-jalur moneter dalam transmisi kebijakan moneter telah banyak dilakukan oleh peneliti sebelumnya. Negara-negara maju dan berkembang menggunakan jalur-jalur moneter yang disesuaikan dengan kondisi perekonomian negaranya. Kawasan Eropa, misalnya, dalam penelitian Jobst dan Lin (2016) mengenai suku bunga terhadap profitabilitas bank menunjukkan bahwa suku bunga negatif mendukung kondisi keuangan dan berkontribusi pada ekspansi kredit, namun, kebijakan pemotongan suku bunga akan membebani profitabilitas bank. Sedangkan hasil penelitian Georgiadis (2015) menunjukkan bahwa transmisi kebijakan moneter yang berada dalam kawasan euro ekonomi menghasilkan asimetri informasi dan sejalan dengan teori ekonomi, serta didorong oleh perbedaan karakteristik struktural ekonomi. Bankbank di Eritria, menunjukkan suku bunga yang tidak mendukung nilai tukar (Mengesha \& Holmes, 2013). Pada negara-negara Asia, hasil penelitian Lee dan Bowdler (2019) menemukan bukti bahwa terhambatnya transmisi kebijakan moneter terletak pada suku bunga. Sebaliknya, penelitian Lombardia, Siklos, dan Xiec (2018) menemukan bahwa suku bunga memainkan 
peranan penting dalam mekanisme transmisi kebijakan moneter di US, zona Euro dan Jepang yang juga sama berperan penting di Cina.

Lebih lanjut, berfokus pada lingkup negara berkembang seperti Indonesia, beberapa penelitian menunjukkan hasil yang serupa. Penelitian Wulandari (2012) tentang efektivitas jalur suku bunga dan kredit dalam transmisi moneter Indonesia menyatakan bahwa jalur suku bunga dan kredit memiliki peran yang penting dalam pengendalian inflasi. Akan tetapi, peran dari jalur suku bunga masih sangat terbatas. Kemudian, Hasibuan dan Pratomo (2015) meneliti mekanisme transmisi kebijakan moneter menggunakan jalur suku bunga di Indonesia menemukan bahwa variabel GDP dan CPI dapat menjelaskan efektivitas transmisi moneter.

Novalina dan Rosiadi (2018) meneliti mengenai efektivitas kebijakan moneter guna menjaga stabilitas ekonomi dan menurunkan kemiskinan di India, Brazil, China, Russia, dan Indonesia menunjukkan bahwa variabel ekonomi sangat dipengaruhi oleh fluktuasi ekspor masing-masing negara, juga oleh stabilitas harga pangan yang diukur dengan inflasi harga makanan. Setidaknya, penelitian Novalina dan Rosiadi (2018), Wulandari (2012) dan Heroika (2011) yang meneliti tentang transmisi kebijakan moneter jalur suku bunga dan nilai tukar dengan simulasi Vector Auto Regressive (VAR) memperoleh hasil bahwa jalur suku bunga merupakan saluran moneter yang paling efektif dibandingkan nilai tukar.

Kendatipun banyak penelitian yang mendukung efektivitas jalur suku bunga di Indonesia, fakta dilapangan menunjukkan bahwa kegagalan prediksi jalur tersebut masih cukup besar. Kurun waktu sepuluh tahun sejak diberlakukannya Inflation Targeting Framework (ITF) masih sangat perlu dievaluasi oleh otoritas moneter. Pasalnya, data publikasi Bank Indonesia menunjukkan bahwa inflasi yang terjadi masih berada jauh dari target yang ditetapkan oleh otoritas meneter dengan rata-rata deviasi mencapai lima persen.

Pemilihan jalur transmisi kebijakan moneter merupakan prioritas penting Bank Indonesia untuk merumuskan kebijakan moneter yang akan diterapkan. Sektor keuangan seperti misalnya Bank berperan penting dalam transmisi kebijakan moneter (Aleem, 2010; Lombardia et al., 2018). Hal ini berkaitan dengan langkah selanjutnya, yaitu pemilihan instrumen dan prosedur dalam pelaksanaan kebijakan moneter. Harapannya, dengan meningkatkan pemahaman mengenai mekanisme transmisi kebijakan moneter dapat mendorong pertumbuhan ekonomi serta menentukan pilihan yang lebih baik dari variabel sasaran (Wulandari, 2012).

Berdasarkan latar belakang tersebut, maka penelitian ini bertujuan untuk mengetahui efektivitas jalur suku bunga, nilai tukar, dan kredit dalam kerangka ITF. Lebih lanjut, penelitian ini juga bertujuan untuk menentukan jalur moneter manakah yang paling tepat digunakan dalam sistem moneter Indonesia.

\section{KAJIAN LITERATUR}

\section{Jalur Transmisi Kebijakan Moneter}

Mekanisme transmisi kebijakan moneter yang terjadi antara bank sentral, perbankan dan pelaku ekonomi akan terhubung kepada perkembangan sektor keuangan dan sektor riil. Hubungan ini terjalin melalui jalur-jalur moneter yang sering dibahas di banyak literatur moneter. Menurut Natsir (2014), perubahan BI-Rate akan mempengaruhi inflasi melalui lima jalur, yaitu: jalur suku bunga, jalur kredit, jalur nilai tukar, jalur harga asset, dan jalur ekspektasi. 
Pendapat lainnya dari seorang ekonom mengemukakan bahwa terdapat lima jalur mekanisme transmisi kebijakan moneter yang sering dikemukakan dalam teori ekonomi, yaitu jalur moneter langsung (direct monetary channel), jalur suku bunga (interest rate channel), jalur harga aset (asset price channel), jalur kredit (credit channel), dan jalur ekspektasi (expectation channel) (Mishkin, 1995).

\subsection{Jalur Suku Bunga (Interest rate Channel)}

Jalur suku bunga bekerja melalui perubahan terhadap suku bunga kredit dan deposito akibat dari perubahan BI-Rate. Ketika perekonomian sedang melambat, Bank Indonesia memutuskan untuk melaksanakan kebijakan moneter ekspansif melalui penurunan BI-Rate. Otoritas moneter berharap bahwa penurunan BI-Rate ini akan direspon oleh perbankan dengan cara menurunkan suku bunga kreditnya. Selanjutnya, dengan penurunan suku bunga kredit tersebut, maka jumlah permintaan kredit oleh masyarakat akan meningkat. Hasilnya, aktivitas konsumsi dan investasi meningkat sehingga perekonomian makin bergairah.

Menurut Romer dan Rommer (1990), ada dua kondisi yang memungkinkan jalur suku bunga untuk bekerja, yaitu: pertama, bank tidak harus secara sempurna mampu melindungi saldo transaksi dari perubahan cadangan, kedua, tidak ada substitusi terdekat uang untuk melakukan transaksi dalam perekonomian. Mishkin (2009) menggambarkan skema kerja jalur suku bunga melalui penurunan suku bunga riil yang menyebabkan penurunan biaya modal dan peningkatan pengeluaran investasi dan konsumsi. Naiknya investasi dan konsumsi pada akhirnya mendorong peningkatan permintaan agregat, kenaikan output dan inflasi.

\subsection{Jalur Nilai Tukar (Exchange rate channel)}

Jalur nilai tukar dalam mekanisme transmisi kebijakan moneter memiliki keterkaitan dengan tingkat ekspor dan impor. Hal ini disebabkan karena kegiatan ekspor dan impor memiliki hubungan yang signifikan dengan nilai tukar suatu negara. Terdepresiasinya mata uang domestik merupakan peluang untuk meningkatkan ekspor, demikian sebaliknya dengan apresiasi mata uang dapat digunakan untuk meningkatkan impor.

Kenaikan BI-Rate akan mendorong kenaikan selisih antara suku bunga domestik dengan suku bunga luar negeri. Investor asing akan lebih tertarik untuk menanamkan modalnya di Indonesia melalui instrumen-instrumen keuangan seperti Sertifikat Bank Indonesia (SBI). Kejadian ini akan menyebabkan peningkatan modal masuk (capital inflow) di Indonesia, dan pada akhirnya akan mendorong nilai rupiah terus naik dibandingkan mata uang asing (rupiah terapresiasi). Selanjutnya, apresiasi nilai tukar akan berdampak pada sektor riil, yakni peningkatan jumlah impor dan penurunan ekspor. Hal ini disebabkan karena peningkatan nilai mata uang domestik menyebabkan harga barang domestik menjadi mahal di mata dunia, dengan kata lain ekspor menjadi kurang kompetitif. Penurunan ekspor ini akan berdampak pada menurunnya pertumbuhan ekonomi (Mishkin, 2009).

Transmisi kebijakan moneter melalui jalur nilai tukar dalam memengaruhi inflasi dapat dijelaskan dengan menggunakan teori Prices and Policy oleh M. Levich. Teori ini mengemukakan bahwa suku bunga memiliki peran yang penting terkait ekuilibirum pasar uang dan pasar valas. Ketika terjadi ketidakseimbangan suku bunga (interest rate parity), maka akan mengakibatkan adanya capital outflow atau capital inflow. Capital outflow akan menyebabkan 
mata uang domestik terdepresiasi, dan akhirnya akan menyebabkan inflasi. Oleh sebab itu, selain upaya untuk menstabilkan inflasi, diperlukan juga upaya menstabilkan mata uang.

\subsection{Jalur Kredit Bank (Credit channel)}

Perbankan memiliki peran yang penting dalam sistem keuangan dalam hal mengatasi masalah informasi di pasar kredit. Oleh karena itu, masyarakat atau peminjam tertentu tidak memiliki akses ke pasar kredit kecuali melalui perbankan. Dalam jalur moneter ini, terdapat satu kondisi yang harus dipenuhi agar kebijakan dapat berjalan dengan baik, yaitu tidak adanya substitusi yang sempurna dari simpanan-simpanan bank ritel dengan sumber pendanaan lainnya.

Mishkin (2009) menjelaskan jalur kredit berawal dari kebijakan ekspansioner yang digagas otoritas moneter kemudian direspon dengan peningkatan cadangan dan simpanan oleh perbankan. Selanjutnya, ketersediaan kredit kepada masyarakat pun meningkat dan akhirnya menyebabkan peningkatan pengeluaran investasi yang disertai dengan pertumbuhan ekonomi.

\section{METODA PENELITIAN}

Penelitian ini bertujuan untuk menganalisis efektivitas kinerja jalur suku bunga, nilai tukar dan kredit dalam kerangka Inflation Targeting Framework (ITF). Lebih lanjut, dengan mengetahui efektivitas masing-masing jalur, maka akan diperoleh jalur yang paling tepat digunakan dalam sistem moneter Indonesia. Oleh karena itu, berdasarkan tujuan tersebut, penelitian ini menggunakan Error Correction Model (ECM). Data yang digunakan merupakan data sekunder yang diambil dari Bank Indonesia periode 2005 hingga 2016. Variabel penelitian yang digunakan meliputi inflasi, BI-rate, suku bunga kredit (sbk), produk domestik bruto (PDB), nilai tukar (kurs), bank reserve (bbr), dan jumlah kredit yang disalurkan. Alasan penggunaan variabel tersebut mengacu pada teori moneter serta berbagai penelitian terdahulu yang sudah dijelaskan sebelumnya.

Pemilihan digunakannya model ECM dalam penelitian ini juga didasarkan bahwa ECM sering dipandang sebagai salah satu model dinamik yang sangat terkenal dan banyak diterapkan dalam studi empirik terutama sejak kegagalan Partial Adjustment Model (PAM) dalam menjelaskan perilaku dinamik permintaan uang berdasarkan konsep stok penyangga dan munculnya pendekatan kointegrasi dalam analisis ekonomi time series. Insukindro (1999) menyatakan bahwa ECM relatif lebih unggul bila dibandingkan dengan PAM, misalnya, karena kemampuan yang dimiliki ECM yang meliputi banyak variabel dalam menganalisis fenomena ekonomi jangka pendek dan jangka panjang serta mengkaji konsisten atau tidaknya model empirik dengan teori ekonometrika, serta dalam usaha mencari pemecahan terhadap persoalan variabel time series yang tidak stasioner dan regresi lancung atau korelasi lancung.

Tahapan pengujian yang dilakukan dalam mengestimasi model ECM adalah sebagai berikut:

\section{A. Uji Stasioneritas}

Data time series seringkali menunjukkan pola yang berfluktuasi. Adanya fluktuasi pada data tersebut akan berdampak pada proses estimasi model. Oleh karena itu, harus dilakukan pengujian untuk mengetahui derajat kestabilan data. Uji yang sering digunakan adalah uji stasioneritas. Dalam uji stasioner ini digunakan Uji Akar Unit (Unit Root Test) atau sering disebut dengan uji Augmented Dickey - Fuller (ADF test). Pengujian stasioneritas dilakukan untuk setiap variabel. Uji ini bertujuan untuk mengetahui apakah 
nilai ekspektasi rata - rata stochastic term error sama dengan nol dan varians konstan maka setiap data runtun waktu dari variabel adalah stasioner (Enders, 2014). Uji ini dilakukan ketika error term saling berkorelasi.

\section{B. Uji Kointegrasi Engle-Granger}

Setelah mengetahui bahwa data time series tidak stasioner, maka langkah selanjutnya adalah melakukan identifikasi apakah data tersebut terkointegrasi. Uji kointegrasi dilakukan untuk menguji keseimbangan jangka panjang hubungan antar variabel meskipun secara individual tidak stasioner namun kombinasi linier dari variabel tersebut dapat menjadi stasioner. Uji kointegrasi dilakukan pada nilai residual model. Uji kointegrasi bertujuan untuk melihat apakah residual yang dihasilkan, stasioner atau tidak stasioner (Engle \& Granger, 1987). Jika residual stasioner berarti bahwa variabel bebas dan terikat terkointegrasi, sebaliknya, dikatakan tidak berkointegrasi (Engle \& Granger, 1987). Dalam ekonometrika varibel yang saling terkointegrasi dikatakan sebagai kondisi seimbang jangka panjang (long run-equilibrium).

\section{Estimasi Model ECM Engle-Granger (ECM EG)}

Kriteria pengujian ECM menurut Widarjono (2016) harus memenuhi dua kondisi, yaitu data tidak stasioner pada derajat level (untuk variabelnya) dan terkointegrasi yang ditunjukkan oleh besarnya nilai statistika ADF atau DF dibandingkan nilai kritisnya atas komponen residual. Penelitian ini menggunakan kointegrasi Engle-Granger (EG) untuk mengetahui ada tidaknya hubungan jangka panjang dalam model. Adapun model ECM EG yang digunakan dalam penelitian ini adalah sebagai berikut:

\section{Model 1: Jalur Suku Bunga}

$$
\Delta \text { inflasi }_{t}=\alpha_{0}+\alpha_{1} \Delta b i_{-} \text {rate }_{t}+\alpha_{2} \Delta s b k_{t}+\alpha_{3} \Delta g d p_{t}+\alpha_{4} E C_{t}+e_{t}
$$

\section{Model 2: Jalur Nilai Tukar}

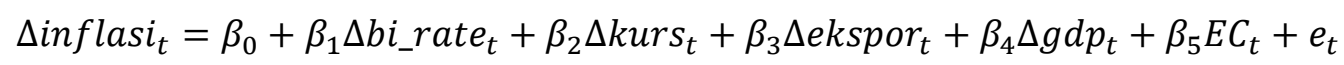

Model 3: Jalur Kredit

$$
\Delta \text { lninflasi }_{t}=\delta_{0}+\delta_{1} \Delta \operatorname{lnbr}_{t}+\delta_{2} \Delta \text { lnkredit }_{t}+\delta_{3} \Delta \operatorname{lng} d p_{t}+\alpha_{4} E C_{t}+e_{t}
$$

Pedoman yang digunakan untuk menyimpulkan apakah model ECM-EG yang digunakan dalam masing-masing model tersebut dikatakan valid yakni dengan melihat nilai-nilai koefisien pada Error correction Term (ECt). Menurut Engle and Granger (1987), model ECM-EG dikatakan valid jika nilai koefisien ECt bernilai negatif dan siginifikan. Artinya, jika estimasi menghasilkan nilai koefisien pada ECt bernilai negatif dan signifikan pada derajat signifikansi $1 \%$, 5\% ataupun 10\%, maka model ECM-EG dikatakan valid dan dapat digunakan untuk menjelaskan proses pengkoreksian dan Analisa lanjutan.

\section{HASIL PENELITIAN DAN PEMBAHASAN}

Tujuan akhir penerapan kebijakan moneter melalui kerangka Inflation Targeting Framework (ITF) adalah menjaga dan memelihara kestabilan nilai rupiah yang salah satunya tercermin dari tingkat inflasi yang rendah dan stabil. Untuk mewujudkannya, Bank Sentral Republik Indonesia berupaya memilih dari sekian kemungkinan digunakannya jalur-jalur 
transmisi kebijakan moneter sehingga diperoleh jalur yang efektif. Dalam penelitian ini, untuk mengetahui efektivitas transmisi kebijakan moneter apakah menggunakan jalur suku bunga, jalur nilai tukar maupun jalur kredit masing-masing jalur, digunakan model ECM. Widarjono (2016) menyatakan bahwa ECM adalah model yang memasukkan penyesuaian untuk melakukan koreksi bagi ketidakseimbangan. Proses pengkoreksian ketidakseimbangan dalam model ECM dilakukan sebagai akibat digunakannya data-data time series yang pada umumnya tidak stasioner. Adapun hasil pengujian berdasarkan tahapan-tahapan dalam eksekusi model ECM adalah sebagai berikut:

\subsection{Stasioneritas}

Data time series memiliki kecenderuangan bergerak dengan pola-pola yang fluktuatif. Pergerakan pola yang fluktuatif tersebut mengakibatkan data-data time series yang digunakan untuk mengestimasi model seringkali menunjukkan hasil yang tidak diharapkan oleh peneliti, salah satunya terjadinya regresi lancung (spurious regression). Untuk menghindari hal tersebut, maka diperlukan pengujian stasioneritas yaitu uji untuk mendeteksi kondisi kestabilan data. Uji yang digunakan untuk mengetahui kestabilan data adalah uji stasioneritas melalui uji Augmented Dickey-Fuller test (ADF test). Berikut adalah output uji stasioneritas pada data-data penelitian.

Tabel 1. Hasil Estimasi Stasioneritas

\begin{tabular}{lcc}
\hline \multicolumn{1}{c}{ Variabel } & Level & First Difference \\
\cline { 2 - 3 } & Nilai Prob. & Nilai Prob. \\
\hline Inflasi & 0.08 & $0.00^{*}$ \\
\hline Bi_rate & 0.40 & $0.00^{*}$ \\
\hline Suku Bunga Kredit (sbk) & 0.39 & $0.03^{* *}$ \\
\hline GDP & 0.97 & $0.00^{*}$ \\
\hline Kurs & 0.95 & $0.00^{*}$ \\
\hline Ekspor & 0.44 & $0.00^{*}$ \\
\hline Bank reserve (bbr) & 0.97 & $0.00^{*}$ \\
\hline Kredit & 0.11 & $0.00^{*}$ \\
\hline
\end{tabular}

Ket. *) signifikan pada $1 \%, 5 \%$, dan $10 \%$; **) signifikan pada $5 \%$, dan $10 \%$

Berdasarkan tabel 1 di atas, dapat diketahui bahwa keseluruhan variabel belum stasioner pada tingkat level dan telah stasioner pada tingkat first difference. Hal tersebut ditunjukkan oleh nilai-nilai $p$-value yang lebih kecil dari derajat kepercayaan $1 \%, 5 \%$, maupun $10 \%$. Terjadinya stasioneritas pada tingkat first difference berarti bahwa variabel-variabel tersebut memiliki kemungkinan terjadinya hubungan jangka panjang tiap variabel dalam model. Oleh karena itu, untuk membuktikan kemungkinan tersebut, maka selanjutnya dilakukan uji kointegrasi EG.

\subsection{Kointegrasi Engle-Granger (EG)}

Widarjono (2016) menyebutkan bahwa uji kointegrasi Engle-Granger dilakukan dengan eksekusi residual yang diperoleh dari persamaan regresi. Kemudian, residual diuji dengan menggunakan Augmented Dickey Fuller (ADF) ataupun Dickey Fuller (DF). Kesimpulan terkointegrasi tidaknya persamaan tersebut dilihat dari perbandingan nilai statistik dan nilai kritis. Jika nilai statistik lebih besar dari nilai kritis, maka model memiliki hubungan jangka panjang, demikian pula sebaliknya. Berikut ditampilkan nilai residual dari tiap model, dalam hal ini adalah model jalur suku bunga, nilai tukar dan kredit. 
Tabel 2. Hasil Estimasi Kointegrasi Engle-Granger

\begin{tabular}{cccc}
\hline Model & \multicolumn{1}{c}{ Residual } & Probabilitas & Keterangan \\
\hline Model 1 & EC1 untuk jalur suku bunga & 0.00 & Terkointegrasi \\
\hline Model 2 & EC2 untuk jalur nilai tukar & 0.00 & Terkointegrasi \\
\hline Model 3 & EC3 untuk jalur kredit & 0.00 & Terkointegrasi \\
\hline
\end{tabular}

Berdasarkan tabel 2 di atas, diperoleh nilai probabilitas EC atau residual dari persamaan regresi pada tingkat level sebesar 0.00. Angka ini menunjukkan bahwa persamaan dalam ketiga jalur moneter tersebut memiliki hubungan jangka panjang. Terpenuhinya syarat ECM, maka eksekusi model dapat dilanjutkan pada tahap selanjutnya. Model yang cocok digunakan Model ECM mensyaratkan adanya stasioneritas pada derajat difference. Kondisi ini kemudian menunjukkan adanya ketidakseimbangan yang akan diselesaikan dalam jangka panjang.

\subsection{Hasil Estimasi Error Correction Model (ECM)}

Variabel ekonomi dalam jangka pendek seringkali mengalami ketidakseimbangan, yang berarti terdapat perbedaan antara apa yang diinginkan oleh pelaku ekonomi dengan kejadian yang sebenarnya. Adanya ketidakseimbangan dalam model membutuhkan penyesuaian untuk kembali ke keadaan yang seimbang. Salah satu model ekonometrika yang dapat digunakan untuk melihat penyesuaian tersebut adalah model ECM. Dalam model ini diperoleh ECT (Error Correction Term), yang menunjukkan kecepatan penyesuaian variabel untuk kembali ke titik keseimbangan. Berikut adalah koefisien ECT yang diperoleh dari eksekusi model ECM jalur suku bunga, nilai tukar dan kredit.

Tabel 3. Koefisien dan Tingkat Signifikansi ECT

\begin{tabular}{cccc}
\hline Model & \multicolumn{1}{c}{ Residual } & Koefisien & P-value \\
\hline Model 1 & ECT untuk jalur suku bunga & -0.954730 & 0.0000 \\
\hline Model 2 & ECT untuk jalur nilai tukar & -0.911957 & 0.0000 \\
\hline Model 3 & ECT untuk jalur kredit & -0.633154 & 0.0003 \\
\hline
\end{tabular}

Berdasarkan tabel 3 di atas, dapat diketahui bahwa model ECM yang digunakan dalam penelitian ini adalah valid, karena nilai koefisien yang diperoleh adalah negatif dan signifikan pada tingkat kepercayaan 5\%. Nampak dari tabel 3 di atas, nilai koefisien ECT untuk jalur kredit lebih kecil dibandingkan jalur suku bunga dan nilai tukar. Hal ini menunjukkan bahwa ketidakseimbangan dalam model ini lebih cepat melakukan penyesuaian dibandingkan jalur suku bunga dan nilai tukar.

Lebih lanjut, ketiga jalur moneter, yaitu suku bunga, nilai tukar dan kredit memiliki kelebihan dan kekurangannya masing-masing. Menelusuri koefisien determinasi dari ketiga model dalam penelitian ini, diperoleh bahwa koefisien determinasi jalur kredit sangatlah rendah jika dibandingkan jalur suku bunga dan nilai tukar. Selain itu, signifikansi variabel independen dalam model kredit hanya terdapat pada satu variabel dari tiga variabel independen yang digunakan. Berbeda dengan jalur suku bunga, kendatipun memiliki penyesuaian yang relatif lama dibandingkan jalur nilai tukar dan kredit, nilai koefisien determinasi pada model ini cukup tinggi mencapai $79 \%$ dengan 2 variabel independen yang signifikan. 


\subsection{Pembahasan}

Efektivitas kinerja jalur moneter dalam mekanisme transmisi kebijakan moneter merupakan urgensi untuk mengevaluasi kinerja otoritas moneter terkait stabilitas harga. Terlebih dalam keadaan dimana kondisi ekonomi global yang tak menentu juga menjadi salah satu faktor yang perlu diperhatikan (Choi \& Lee, 2010). Terlebih lagi, efektivitas saluran jalur moneter akan berbeda untuk setiap negara bahkan sangat spesifik, serta bergantung pada berbagai hal-hal lain terkait struktur keuangan (Mishra, Montiel, \& Spilimbergo, 2012). Rezim Inflation Targeting Framework (ITF) bertujuan untuk menjaga fluktuasi harga agar tetap stabil dan berada pada range target yang telah ditetapkan. Pentingnya stabilitas harga tersebut berkaitan erat dengan kredibilitas Bank Indonesia sebagai penentu arah perekonomian dalam konteks moneter. Semakin seringnya ketidaktepatan dalam memprediksi target inflasi akan berdampak pada turunnya kredibilitas bank sentral di mata masyarakat.

Penelitian yang dilakukan oleh Mishra, Montiel, dan Sengupta (2016) mengenai efektifitas transmisi moneter di negara berkembang, khususnya India menunjukkan bahwa jalur nilai tukar memberikan respon terhadap gunjangan kebijakan moneter diarah yang benar namun dengan besaran yang kecil. Implikasinya, menurut Mishra et al., (2016), menyimpulkan bahwa setiap dampak kebijakan moneter terhadap permintaan agregat di India lebih cenderung beroperasi melalui neraca perdagangan daripada melalui komponen-komponen permintaan agregat yang sensitif pada tingkat bunga, tetapi setiap efek menunjukkan kecenderuangan lemah.

Berdasarkan pada hasil estimasi model ECM pada tabel 3 menunjukkan pada jalur suku bunga, nilai tukar dan kredit sebagai transmisi kebijakan moneter menunjukkan hasil yang cukup jelas. Berdasarkan hasil estimasi pada tabel 3, penyesuaian ketidakseimbangan paling cepat ditunjukkan oleh model ketiga, yaitu transmisi melalui saluran kredit perbankan. Ketidakseimbangan yang terjadi dalam jangka pendek, dapat diselesaikan dalam kurun waktu enam kuartalan mendatang. Cepatnya penyesuaian transmisi moneter melalui jalur kredit berkaitan erat dengan kuatnya peran kredit perbankan terhadap pertumbuhan ekonomi di Indonesia. Kebijakan moneter yang kontraktif akan sangat kuat direspon oleh perbankan. Kebijakan kontraktif memaksa bank untuk mengurangi kucuran kredit kepada masyarakat. Berkurangnya kredit menyebabkan tingkat konsumsi dan investasi pun menurun, yang pada akhirnya menyebabkan perekonomian lesu. Kemudian, perekonomian yang lesu akan menyebabkan terjadinya penurunan pertumbuhan ekonomi dan inflasi.

Cepatnya penyesuaian jalur kredit dibandingkan jalur suku bunga dan nilai tukar sejatinya menunjukkan efektivitas jalur kredit dalam transmisi kebijakan moneter. Jika dibandingkan dengan kedua jalur lainnya, yaitu suku bunga dan nilai tukar, maka dapat dikatakan bahwa jalur kredit memiliki kinerja yang lebih baik dua lainnya. Hasil ini sejalan dengan penelitian yang dilakukan oleh Wulandari (2012) yang menyatakan bahwa jalur kredit juga memainkan peran penting dalam transmisi moneter Indonesia, selain suku bunga. Peran suku bunga yang dikemukakan oleh Wulandari (2012) masih sangat terbatas, yang identik dengan lambatnya penyesuaian ketidakseimbangan pada jalur suku bunga yang ditunjukkan melalui tabel 3 .

Hasil yang berbeda dikemukakan oleh Heroika (2011) dan Aleem (2010) yang menyatakan bahwa jalur suku bunga merupakan jalur yang efektif dalam transmisi kebijakan moneter. Kesimpulan tersebut nampak kurang relevan dengan kondisi saat ini, dimana fakta 
menunjukkan bahwa target inflasi masih sering meleset dari nilai aktualnya. Berikut ditampilkan target inflasi dan nilai aktualnya yang dipublikasikan oleh Bank Indonesia.

\section{Tabel 4. Target Inflasi dan Nilai Aktual}

\begin{tabular}{rrr}
\hline Tahun & Target & Aktual \\
\hline 2005 & $6 \pm 1 \%$ & 17,11 \\
\hline 2006 & $8 \pm 1 \%$ & 6,60 \\
\hline 2007 & $6 \pm 1 \%$ & 6,59 \\
\hline 2008 & $5 \pm 1 \%$ & 11,06 \\
\hline 2009 & $4,5 \pm 1 \%$ & 2,78 \\
\hline 2010 & $5 \pm 1 \%$ & 6,96 \\
\hline 2011 & $5 \pm 1 \%$ & 3,79 \\
\hline 2012 & $4,5 \pm 1 \%$ & 4,30 \\
\hline 2013 & $4.5 \pm 1 \%$ & 8,38 \\
\hline 2014 & $4.5 \pm 1 \%$ & 8,36 \\
\hline 2015 & $4 \pm 1 \%$ & 3,35 \\
\hline 2016 & $4 \pm 1 \%$ & 3,02 \\
\hline
\end{tabular}

Berdasarkan tabel 4, terlihat bahwa jalur Suku Bunga yang saat ini digunakan oleh Bank Sentral dalam mengelola target inflasi seringkali menghasilkan besaran yang tidak seperti ditargetkan. Dengan kata lain, kecenderungan otoritas moneter yang menggunakan saluran suku bunga dipandang masih kurang kuat untuk merespon sasaran akhir, yaitu inflasi. Hal ini dapat terjadi berkaitan dengan reaksi perbankan dalam merespon penurunan maupun kenaikan suku bunga kebijakan. Perbankan masih sangat lamban bahkan enggan merespon perubahan suku bunga kebijakan karena secara langsung berkaitan dengan profitabilitasnya. Lag yang diperoleh dari perubahan suku bunga kebijakan ke suku bunga perbankan akan sangat panjang, sehingga menyebabkan rangsangan untuk menstabilkan harga akan cenderung lemah. Sebagai gambaran lemahnya transmisi jalur suku bunga dalam sistem moneter dapat ditunjukkan oleh simulasi Impulse Response Function (IRF) di bawah ini.

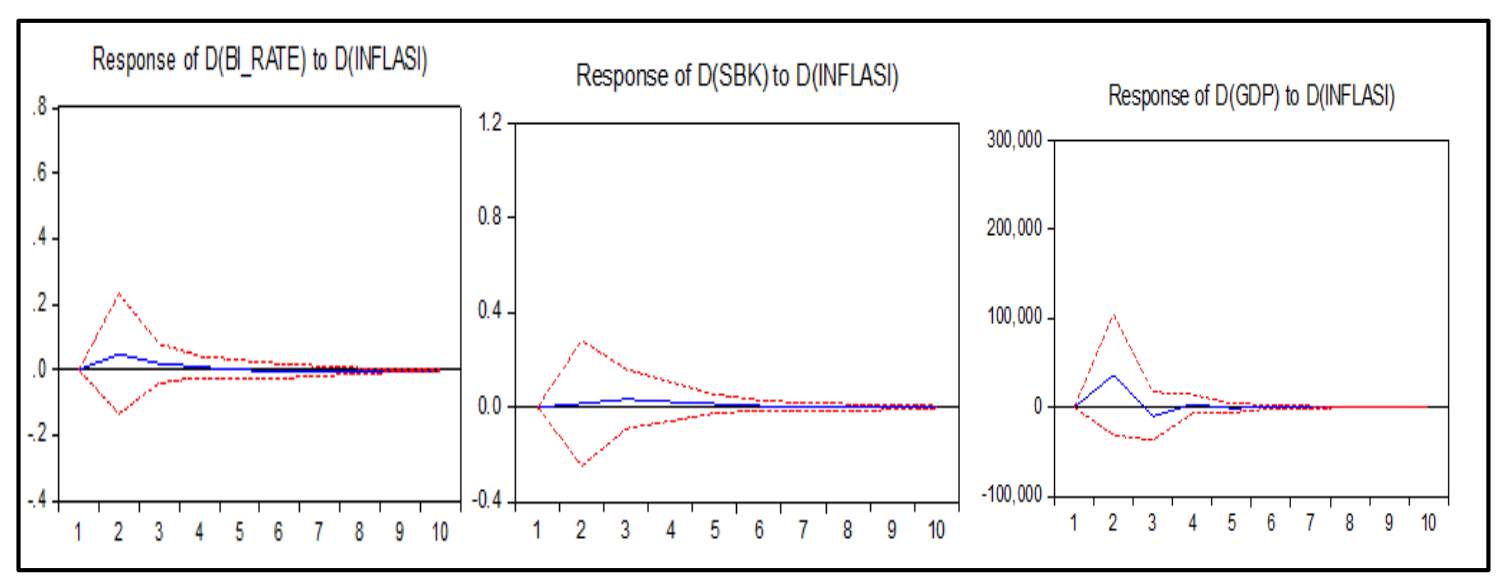

Gambar 1. Simulasi Impulse Response Function (IRF) Jalur Suku Bunga

Berdasarkan impulse response function pada gambar 1 di atas, dapat dikonfirmasi bahwa kinerja saluran suku bunga dalam merangsang inflasi masih sangat lemah. Nampak dari gambar 
di 1 atas, bahwa respon bi_rate, suku bunga kredit dan GDP dalam jangka panjang cenderung melemah, yang artinya bahwa pengaruh ketiga variabel tersebut terhadap inflasi semakin lama semakin berkurang. Kebijakan pemerintah untuk merangsang atau menstabilkan inflasi melalui bi_rate, suku bunga kredit dan GDP akan memberikan hasil yang tidak begitu baik.

\section{SIMPULAN}

Tujuan penelitian ini untuk mengetahui efektifitas jalur transmisi kebijakan moneter dalam mempengaruhi tingkat harga antara penggunaan jalur suku bunga, nilai tukar dan kredit. Efektivitas jalur moneter setiap negara akan berbeda, tergantung dari struktur ekonomi dan rezim kebijakan moneter serta faktor terkait lainnya. Dalam penelitian ini, untuk mengukur efektivitas transmisi kebijakan moneter, berdasarkan eksekusi model ECM pada jalur suku bunga, nilai tukar dan kredit, diperoleh nilai ECT yang valid untuk ketiga jalur tersebut. Nilai ECT jalur kredit jauh lebih kecil dibandingkan dua jalur lainnya, yang artinya bahwa ketidakseimbangan dalam jangka pendek akan lebih cepat diatasi dengan menggunakan jalur kredit. Oleh karena itu, dapat disimpulkan bahwa jalur kredit memiliki kinerja yang lebih baik (lebih efektif) dibandingkan jalur suku bunga dan nilai tukar. Selanjutnya, Bank Sentral dapat mempertimbangkan digunakannya jalur kredit dibandingkan jalur suku bunga, maupun jalur nilai tukar.

\section{DAFTAR PUSTAKA}

Aleem, A. (2010). Transmission Mechanism of Monetary Policy in India. Journal of Asian Economics, 21, 186-197. https://doi.org/10.1016/j.asieco.2009.10.001

Alia, S. Z., \& Anwar, S. (2017). Exchange Rate Pass through, Cost Channel to Monetary Policy Transmission, Adaptive Learning, and the Price Puzzle. International Review of Economics and Finance, 48, 69-82. https://doi.org/10.1016/j.iref.2016.11.010

Ascarya, A. (2002). Instrumen-Instrumen Pengendalian Moneter (Seri Kebanksentralan). Retrieved from https://www.bi.go.id/id/publikasi/seri-kebanksentralan/documents/3. instrumen-instrument pengendalian moneter.pdf

Choi, W. G., \& Lee, I. H. (2010). Monetary Transmission of Global Imbalances in Asian Countries. In IMF Working Paper.

Enders, W. (2014). Applied Econometrics Time Series (4th ed.). Wiley.

Engle, R. F., \& Granger, C. W. J. (1987). Co-Integration and Error Correction: Representation, Estimation, and Testing. Econometrica, 55(2), 251-276. Retrieved from http://www.ntuzov.com/Nik_Site/Niks_files/Research/papers/stat_arb/EG_1987.pdf

Georgiadis, G. (2015). Examining Asymmetries in the Transmission of Monetary Policy in the Euro Area: Evidence from A Mixed Cross-Section Global VAR model. European Economic Review, 75, 195-2015. https://doi.org/10.1016/j.euroecorev.2014.12.007

Hasibuan, S., \& Pratomo, W. A. (2015). Mekanisme Transmisi Kebijakan Moneter Melalui Suku Bunga SBI Sebagai Sasaran Operasional Kebijakan Moneter dan Variabel Makroekonomi Indonesia. Jurnal Ekonomi Dan Keuangan, 1(12), 27-40. Retrieved from 
https://media.neliti.com/media/publications/14771-ID-mekanisme-transmisi-kebijakanmoneter-melalui-suku-bunga-sbi-sebagai-sasaran-ope.pdf

Heroika, T. S. (2011). Membandingkan Transmisi Kebijakan Moneter di Indonesia Dengan Var Model: Tradisional Interest Rate Channel, dan Exchange Rate Channel Periode 19902009. Universitas Indonesia.

Insukindro, I. (1999). Pemilihan Model Ekonomi Empirik dengan Pendekatan Koreksi Kesalahan. Jurnal Ekonomi Dan Bisnis Indonesia, 14(1), 1-13.

Jobst, A., \& Lin, H. (2016). Negative Interest Rate Policy (NIRP): Implications for Monetary Transmission and Bank Profitability in the Euro Area (No. WP/16/172).

Lee, S., \& Bowdler, C. (2019). Banking Sector Globalization and Monetary Policy Transmission: Evidence from Asian Countries. Journal of International Money and Finance, 93, 101116. https://doi.org/10.1016/j.jimonfin.2018.12.011

Lombardia, D., Siklos, P. L., \& Xiec, X. (2018). Monetary Policy Transmission in Systemically Important Economies and China's impact. Journal of Asian Economics, 59, 61-79. https://doi.org/10.1016/j.asieco.2018.09.003

Mengesha, L. G., \& Holmes, M. J. (2013). Monetary Policy and Its Transmission Mechanisms in Eritrea. Journal of Policy Modeling, 35, 766-780. https://doi.org/10.1016/j.jpolmod.2013.06.001

Mishkin, F. . (1995). The Economics of Money, Banking, and Financial Markets (4th ed.). New York: Harper Collins.

Mishkin, F. . (2009). Ekonomi Uang, Perbankan, dan Pasar Keuangan (8th ed.). Jakarta: Salemba Empat.

Mishra, P., Montiel, P. J., \& Spilimbergo, A. (2012). Monetary Transmission in Low-Income Countries: Effectiveness and Policy Implications. IMF Economic Review, 60(2), 270-302.

Mishra, P., Montiel, P., \& Sengupta, R. (2016). Monetary Transmission in Developing Countries: Evidence from India. In IMF Working Paper.

Natsir, M. (2014). Ekonomi Moneter \& Kebanksentralan. Jakarta: Mitra Wacana Media.

Novalina, A., \& Rosiadi, R. (2018). Monetary Policy Transmission : Does Maintain the Price and Poverty Stability is Effective? JEJAK (Jurnal Ekonomi Dan Kebijakan), 11(1), 78-91. Retrieved from https://journal.unnes.ac.id/nju/index.php/jejak/article/view/12652/7602

Romer and Rommer, D. H. (1990). New Evidance on Monetary Transmission Mechanism. Brookings Papers on Economic Activity, 1, 149-198. Retrieved from https://www.brookings.edu/wp-

content/uploads/1990/01/1990a_bpea_romer_romer_goldfeld_friedman.pdf

Rüth, S. K. (2017). State-Dependent Monetary Policy Transmission and Financial Market Tensions. Economics Letters, 157, 56-61. https://doi.org/10.1016/j.econlet.2017.05.008

Voinea, L., Lovin, H., \& Cojocaru, A. (2018). The Impact of Inequality on the Transmission of Monetary Policy. Journal of International Money and Finance, 85, 236-250. https://doi.org/10.1016/j.jimonfin.2017.11.007 
Warjiyo, P., \& Solikin. (2003). Kebijakan Moneter di Indonesia. Jakarta: Bank Indonesia.

Widarjono, A. (2016). Ekonometrika Pengantar dan Aplikasinya. Yogyakarta: UPP STIM YKPN.

Wulandari, R. (2012). Do Credit Channel and Interest Rate Channel Play Important Role in Monetary Transmission Mechanism in Indonesia? : A Structural Vector Autoregression Model. Procedia - Social and Behavioral Sciences, 65, 557-563. Retrieved from https://core.ac.uk/download/pdf/81951361.pdf 